ISSN: 2637-4749

\title{
An Introductory to Fasciolosis
}

\author{
Tewodros Alemneh $^{1 *}$, Mebrate Getabalew $^{2}$ and Dawit Akeberegn ${ }^{3}$ \\ ${ }^{1}$ Woreta Town Office of Agriculture and Environmental Protection, Ethiopia \\ ${ }^{2}$ Department of Animal Science, Debre Berhan University, Ethiopia
}

${ }^{3}$ Debre Berhan City Municipality Office, Meat Inspection and Hygiene, Ethiopia

*Corresponding author: Tewodros Alemneh, Woreta Town Office of Agriculture and Environmental Protection, South Gondar Zone, Amhara Regional State, Ethiopia

\begin{abstract}
Fasciolosis is a disease of sheep, cattle, goats and occasionally humans. It is caused by a trematode called Fasciola with the two most common species of Fasciola hepatica (F. hepatica) and Fasciola gigantica (F. gigantica). The parasites encyst in the bile ducts and liver parenchyma of animals. Fasciolosis is common in marshy water bodies where favorable for its intermediate host. Snails of the genus Lymnae facilitate its survival and ubiquity worldwide. The disease causes serious economic losses annually, either directly or indirectly, by disrupting animal production. Therefore; this introductory review highlights on the occurrence, epidemiology, diagnosis, treatment, prevention and control of fasciolosis.
\end{abstract}

Keywords: Fasciolosis; Occurrence; Epidemiology; Diagnosis; Treatment; Prevention; Control

\section{Introduction}

Fasciolosis (liver fluke) is one of the most common economically important parasitic diseases of domestic livestock, in particular cattle, sheep, goat and occasionally man. The disease is major cause for the considerable economic losses (direct or indirect) in cattle industry, mainly through mortality, liver condemnation, reduce production of milk, meat and expenditure for anthelmintics [1]. The disease is caused by digenean trematodes of the genus Fasciola, commonly known as liver flukes. The two species most commonly implicated, as the etiological agents of fasciolosis are $F$. hepatica and F. gigantica. It is a serious disease of grazing animal [2].

Loss due to fasciolosis is associated with mortality, reduced growth rate, reduction in weight gain and unthriftines, reduction in working power, condemnation in large number of infected liver, increased susceptibility to secondary infection and expense due to control measure [3].

The geographic distribution of Fasciola species is dependent on the distribution of suitable species of snails such as Lymnae natalensis and Lymnae truncatula, the most common intermediate hosts 'and usually associated with herds and flocks grazing wet marshy land area. Both Lymnae species are needed for the parasites life cycle to be completed. According to Piedrafita et al. [4], the distribution of fasciolosis is associated with the favorable climatic and ecological conditions for development, spread and maturity of parasite and its life cycle stages in various areas. In view of the worldwide spread occurrence and zoonotic nature, fasciolosis has emerged as a major global and regional concern affecting all domestic animals and infection is most prevalent in regions with intensive cattle production [5].

The disease is found in more water lodged and marshy grazing filed condition anticipated to be ideal for the propagation and maintenance of high prevalence of fasciolosis. In Ethiopia, the highlands contain pockets of water logged marshy areas. this provide suitable habitats year round for the snail intermediate hosts [6]. More rational prophylactic program based on local epidemiological information is needed for sound fasciolosis control strategies in Ethiopia [3]. 
Liver fluke (F. hepatica) is a parasite affecting a range of livestock and other species. Final hosts in which it can develop to sexual maturity include livestock such as sheep, cattle, horses, pigs, goats, alpacas and deer. Other species include kangaroos, wallabies, rabbits, and humans. The adult worms inhabit the bile ducts and gall bladder of the infected animals, causing severe damage which may lead to death. The disease is characterized by anemia due to severe liver damage caused by immature fluke tunneling through the liver parenchyma with extensive hemorrhage that culminates in severe clinical disease. Several complication including weight loss, drop in milk production, submandibular edema, significant morbidity, mortality and diarrhea have been reported in liver fluke infection [7]. Therefore, this review highlights on the occurrence, epidemiology, diagnosis, treatment, and prevention and control of fasciolosis.

\section{Liver Fluke Infection}

Among many parasitic problems of farm animals, fasciolosis is a major disease, which imposes and indirect economic impact on livestock production, particularly of sheep and cattle. Fasciola hepatica and Fasciola gigantica are the two liver flukes commonly reported to cause fasciolosis in ruminants [8]. Fasciolosis caused by the trematode $F$. hepatica is a worldwide parasitic disease and common in ruminants, especially in cattle, buffaloes, sheep, goats, and swine. It occasionally affects humans. Once ingested, parasites migrate through the liver parenchyma to reach the bile ducts. The disease is responsible for considerable economic losses in the cattle industry, mainly through mortality, liver condemnation, reduced production of meat, milk, and wool, and expenditures for anthelmintic [8,9]. Fasciolosis is most common and wide spread disease affecting all species of ruminant animals. Liver fluke disease can be acute, sub-acute or chronic, depending on the size of the infection and how quickly it is acquired [10].

During the early stages, the flukes migrate rather extensively through the tissue of the liver casing considerable mechanical distraction, usually visible as tracks on the capsule of the liver. The damage is due to the feeding of the parasites on liver cells and there may be hemorrhage. The parasites feed almost exclusively on the hepatic cells. In older infection, there is excessive leucolytic infiltration and the terminal part of the migratory tract contains enormous number of invading leucolytics, broken hepatic cells and blood. The spines of the parasite irritate the tissue of the liver resulting in inflammation and fibrosis. The pathological manifestations depend mainly on the number of metacercariae of Fasciola are ingested in first attempt. This results in either acute or even per acute fasciolosis, sub-acute fasciolosis; or chronic fasciolosis. Acute fasciolosis is less common than chronic and is invariably seen in sheep [11].

\section{Etiology}

Fascioliasis is a waterborne and food borne zoonotic disease caused by two parasites of class Trematoda, genus Fasciola; namely
F. hepatica and F. gigantica. Humans are incidental hosts and become infected by ingesting contaminated watercress or water. The illness occurs worldwide, particularly in regions with intensive sheep or cattle production. Incidence of human infection has increased over the past 20 years. Because of the large numbers of people and animals infected worldwide, fascioliasis causes considerable morbidity. In children, fascioliasis is often associated with severe anemia, although it is seldom fatal [4].

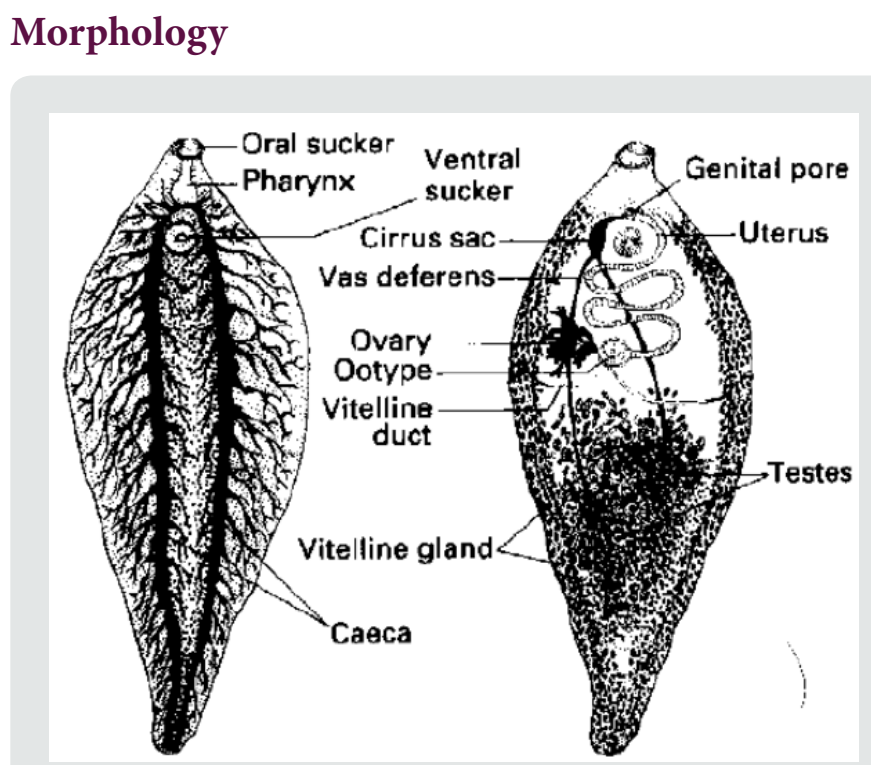

Figure 1: The Structure of Fasciola hepatica [11].

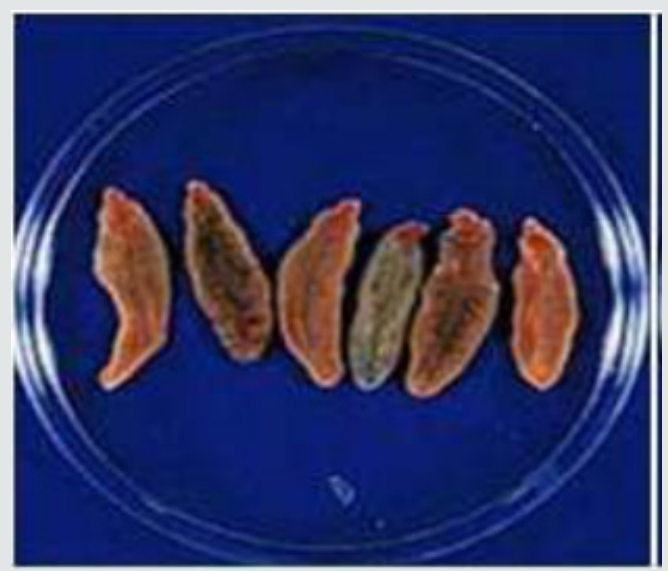

Figure 2: Collected Fasciola worms from the slaughter house cattle [13].

Adult worm is a large leaf-shaped fluke, measuring $3 \mathrm{~cm}$ in length by $1.5 \mathrm{~cm}$ in width and brown to pale grey in color. There are two suckers, the oral sucker is smaller. The anterior end bearing the oral sucker forms a conical projection. The posterior end is rounded. The acetabulum is situated in a line with the two shoulders formed by the broadening of the conical projection posteriorly. The adult possesses two suckers for attachment. The oral sucker at the anterior end surrounds the mouth and the ventral, as the name indicates, is on that surface. The body surface is a tegument which is absorptive and is often covered with spines. The muscles lie 
immediately below the tegument. There is no body cavity and the organs are packed in a parenchyma (Figure 1). The digestive system is simple, the oral opening leading into a pharynx, esophagus and a pair of branched intestinal caeca which end blindly. Undigested material is presumably regurgitated. The excretory system consists of a large number of ciliated tame cells, which impel waste metabolic products along a system of tubules which ultimately join and open to the exterior (Figure 2). The nervous system is simple, consisting of a pair of longitudinal trunks connecting anteriorly with two ganglia $[11,12]$.

\section{Epidemiology}

The geographical distribution of trematode species is dependent on the distribution of suitable species of snails. The genus Lymnaea, in general and Lymnaea trancatula and Lymnaea natalensis, in particular are the most common intermediate hosts for $F$. hepatica and F. gigantica, respectively. Fasciola hepatica has a cosmopolitan distribution, mainly in temperate zones, while $F$ gigantica is found in tropical regions of Africa and Asia [13]. Different works so far conducted in Ethiopia reported variable prevalence rates of bovine fasciolosis in different localities of the country. Fasciola hepatica was shown to be the most important fluke species in Ethiopian livestock with distribution of over three quarter of the nation except in the arid north-east and east of the county [14]. The distribution of $F$ gigantica is mainly localized in the western humid zone of Ethiopia that encompasses approximately one fourth of the nation. In Ethiopia, F. hepatica and F. gigantica infections occur in areas above 1800 m.a.s.l. and below 1200 m.a.s.l, respectively, which has been attributed to variations in the climatic and ecological conditions such as rain fall, altitude, temperature and livestock management system $[3,7,15]$. There are many risk factors which expose the occurrence of the parasitic disease of fasciolosis like age, sex and body condition of the animals. According to Urquhart et al. [11] and Rickard [12], there are three main factors influencing the production of the large numbers of metacercariae necessary for outbreaks of fasciolosis.

\section{Availability of suitable snail habitats}

Lymnaea truncatula prefers wet mud to free water, and permanent habitats include the banks of ditches or streams and the edges of small ponds. Following heavy rainfall or flooding, temporary habitats may be provided by hoof marks, wheel ruts or rain ponds. Fields with clumps of rushes are often suspect sites. Though a slightly acid pH environment is optimal for Lymnaea, excessively acid $\mathrm{pH}$ levels arc detrimental, such as occur in peat bogs, and areas of sphagnum moss.

\section{Temperature}

A mean day /night temperature of $10{ }^{\circ} \mathrm{C}$ or above is necessary both for snails to breed and for the development of Fasciola hepatica within the snail and all activity ceases at $5{ }^{\circ} \mathrm{C}$. This is also the minimum range for the development and hatching of Fasciola hepatica eggs. However, it is only when temperatures rise to $15^{\circ} \mathrm{C}$ and are maintained above that level, that a significant multiplication of snails and fluke larval stages ensues.

\section{Moisture}

The ideal moisture conditions for snail breeding and the development of Fasciola hepatica within snails are provided when rainfall exceeds transpiration, and field saturation is attained. Such conditions are also essential for the development of fluke eggs, for miracidia searching for snails and for the dispersal of cercariae being shed from the snails.

\section{Life Cycle}

The essential point of the life cycle is that whereas one nematode egg can develop into only one adult, one trematode egg may eventually develop into hundreds of adults. This is due to the phenomenon of paedogenesis in the molluscan intermediate host, i.e. the production of new individuals by single larval forms. The adult flukes are always oviparous and lay eggs with an operculum or lid at one pole. In the egg, the embryo develops into a pyriform (pear-shaped), ciliated larva called a miracidium. The miracidium, propelled through the water by its cilia, does not feed and must, for its further development, find a suitable snail within a few hours. It is believed to use chemotactic responses to 'home' on the snail and, on contact, it adheres by suction to the snail and penetrates its soft tissues aided by a cytolytic enzyme. The entire process of penetration takes about 30 minutes after which the cilia are lost and the miracidium develops into an elongated sac, the sporocyst, containing a number of germinal cells. These cells develop into rediae which migrate to the hepato-pancrcas of the snail; rediae are also larval forms possessing an oral sucker, some flame cells and a simple gut. From the germinal cells of the rediae arise the final stages, the cereariae, although if environmental conditions for the snail are unsuitable, a second or daughter generation of rediae is often produced instead. The cercaria, young flukes with long tail emerge actively from the snail usually in considerable number. Once a snail is infected, cercariae continue to be produced indefinitely although the majority of infected snails die prematurely from gross destruction of the hepatopancreas. Typically the cercariae swim for some time, utilizing even a film of water, and within an hour or so attach themselves to vegetation, shed their tails and encyst. This stage is called a metacercaria. Encysted metacercariae have great potential for survival extending to months. Once ingested, the outer cyst wall is removed mechanically during mastication. Rupture of the inner cyst occurs in the intestine and depends on a hatching mechanism, enzymatic in origin, triggered by a suitable oxidationreduction potential and a $\mathrm{CO}_{2}$ system provided by the intestinal environment. The emergent juvenile fluke then penetrates the intestine and migrates to the predilection site where it becomes adult alter several weeks. Definitive host acquires infection by ingesting metacercariae on vegetation; fluke penetrates the small 
intestine to abdominal cavity, migrates to and penetrates liver in 4-6 days; migrates throughout liver for 4-7 weeks and then enters bile ducts and matures (Figure 3). Prepatent period is 8-12 weeks; may live for several years $[11,12,14]$.

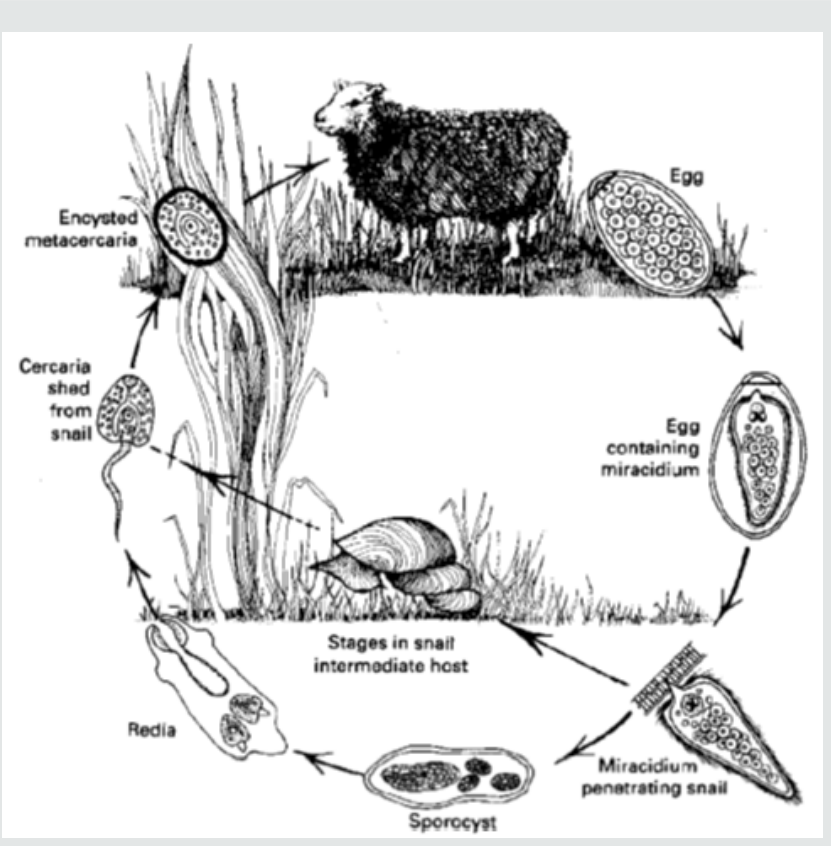

Figure 3: The Life Cycle of Fasciola hepatica [11].

\section{Pathogenesis and Clinical Signs}

These vary according to the phase of parasitic development in the liver and the species of host involved. Essentially the pathogenesis is two-fold; the first phase occurs during migration in the liver parenchyma and is associated with liver damage and hemorrhage. The second occurs when the parasite is in the bile ducts, and results from the haematophagic activity of the adult flukes and from damage to the biliary mucosa by their cuticular spines. Migration of immature flukes causes traumatic hepatitis and hemorrhage; anemia may result; migratory tracts eventually heal by fibrosis. Adults ingest blood and may also cause anemia; presence of adults causes extensive proliferation of the bile duct epithelium, cholangitis, and necrosis of the ductal wall; fibrosis of the lamina propria of the bile duct occurs that may eventually calcify $[9,11,13]$.

\section{Clinical disease occurs in three forms}

Acute: Caused by short-term intake of massive numbers of metacercariae Over 2000; that invade the liver all at once; clinical signs include in appetence, weight loss, abdominal pain, anemia, ascites, depression, sudden death; course is only a few days; occurs primarily in sheep and goats.

Sub-acute: Also caused by intake of massive numbers of metacercariae, but over a longer period of time; clinical signs include in appetence, decreased weight gain or weight loss, progressive hemorrhagic anemia, liver failure, and death; course is 4-8 weeks.

Chronic: It occurs 4-5 months after the ingestion of moderate numbers, 200-500, of metacercariae. The principal pathogenic effects arc anemia and hypoalbuminaemia and more than $0.5 \mathrm{ml}$ blood per fluke can be lost into the bile ducts each day. Additional clinical signs include decreased feed intake and weight gain, reduced milk yield, anemia, emaciation, submandibular edema, ascites; cattle tend to exhibit chronic disease [11,12].

\section{Diagnosis}

Fasciolosis should be considered when there are deaths, anemia or ill thrift in sheep or cattle grazing on fluke-prone country. In live animals, chronic fasciolosis is indicated by fluke eggs in fecal samples. The sampling technique is generally reliable in sheep but much less so in cattle. Diagnosis in dead animals relies on seeing mature or immature fluke in the liver. Necropsy will also identify other conditions that may be contributing to the problem. A serological test (ELISA) is also available for fasciolosis. It detects infection with both immature and adult fluke in a flock or herd, but it is not sensitive enough for diagnosis in individual animals $[7,11]$.

The oval, speculated, golden brown eggs $(130-150 \times 65-90 \mu \mathrm{m})$ must be distinguished from those of paramphistomes (rumen flukes), which are larger and clear. Eggs of $F$. hepatica cannot be demonstrated in feces during acute fasciolosis. In sub-acute or chronic disease in cattle, the number varies from day to day, and repeated fecal sedimentation may be required. Diagnosis can be aided by an ELISA (commercially available in Europe) that enables detection approximately 2-3 weeks after infection and well before the patent period. Plasma concentrations of $\gamma$-glutamyltransferase, which are increased with bile duct damage, are also helpful during the late maturation period when flukes are in the bile ducts. At necropsy, the nature of the liver damage is diagnostic. Adult flukes are readily seen in the bile ducts, and immature stages may be squeezed or teased from the cut surface $[13,15]$.

\section{Treatment and Control}

The treatment recommended will depend on the nature of the disease. Some of the available anthelmintic are not effective against immature fluke and so are not recommended in acute fluke outbreaks. Also, they are less efficient for the strategic control of fasciolosis. The best prevention and control can be achieved with drugs such as Triclabendazole, which are effective against early immature and adult fluke [8,9].

\section{Strategic Control}

Due to the great biotic potential of $F$. hepatica and their intermediate host snails, only a continuous and coordinated strategic application of all available measures can provide economic control of the disease. Control should be on a preventive rather 
than a curative basis. As outlined by Ahmed et al. [8] and Fufa et al. [7], for effective control:

i. Use strategic anthelmintic treatment, to reduce the number of fluke in the host and the number of fluke eggs in pasture;

ii. Reduce the number of intermediate host snails using molluscicide and improve drainage.

iii. Manage fluke-prone areas, to reduce exposure to infection.

\section{Conclusion}

Fasciolosis is the major hurdle for ruminant production by direct or indirect losses at different parts of the world. As a result, the following measures should be taken to control the disease:

i. Dry marshy or wet areas to reduce snail population;

ii. Improve the management system (grazing practice, housing, as well as watering of animals);

iii. Use biological control methods like, frog, birds, etc.;

iv. Administration of appropriate anthelmintics like Triclabendazole while the animal is infected.

\section{Acknowledgements}

Authors' deepest gratitude forwarded to those who had participated and supported this work to become available worldwide for the entire clock to readers and investigators.

\section{Authors Contribution}

Mebrate Getabalew: - Retrieved all the necessary materials, and drafted the article;

Dawit Akeberegn: - Revised the draft and added improvements;

Tewodros Alemneh: - Further reviewed the article and got to be published.

\section{Conflicting of Interests}

Authors declare that no conflicting of interests.

\section{References}

1. Hillyer GV, Apt W (1997) Food-borne trematode infections in the Americas. Trends in Parasitology 13(3): 87-88.

2. Torgerson P, Claxton J (1999) Epidemiology and control. In: Dalton JP (Eds.), Fasciolosis. CAB International oxon, pp. 113-149.

3. Yilma J, Malone JB (1998) A Geographic Information System, forecast model for control of fasciolosis in Ethiopia. vet parasitol 78(2): 103-127.

4. Piedrafita D, Spithill TW, Smith RE, Raadsma HW (2010) Improving animal and human health through understanding liver fluke immunology. Par Imm 32(8): 572-581.

5. WHO (1995) Control of Food-borne trematodes infections. Technical Report series 849: 61-63.

6. Solomom W, Abebe W (2007) Effect of a Strategic Anthelmintic treatment intervention Bovine fasciolosis: A study conducted in facilities endemic area in northwestern Ethiopia. Ethiop vet J 11(2): 59-68.

7. Fufa A, Loma A, Bekele, M, Alemayehu R (2009) Bovine fasciolosis; coprological, abattoir survey and its economic impact due to liver condemnation at Soddo Municipal abattoir, Southern Ethiopia. Trop Anim Health prods 12(3): 221-240.

8. Ahmed S, Nawaz M, Gul R, Zakir M, Razzaq A (2005) Diversity and Prevalence of Trematodes in liver of Sheep and Goat in Quetta, Pakistan. pak J Zool 37: 205-210.

9. Roberts JA, Suhardono (1996) Approaches to control fasciolosis in Ruminants. International Journal for parasitology 26(8-9): 971-981.

10. Radiostis OM, Gray CC, Hinchelift KW, Constable PD (2007) A text book of the disease of cattle, horses, sheep, pigs, and goats. Veterinary Medicine (10 ${ }^{\text {th }}$ edn), Saunders Elsevier, London, UK, England, pp. 295-321.

11. Urquhart HM, Armour J, Duncan JL, Dunn AM, Jennings FW (1996) Veterinary Parasitology. ( $\left.2^{\text {nd }} e d n\right)$, Black well Science Ltd, London, UK, England, pp. 301-309.

12. Rickard BL (2001) The Practical Veterinarian. Veterinary Parasitology pp. 273-302.

13. Javid A, Kuchai JA, Chishti MZ, Manal M, Zaki SA, et al. (2011) Some Epidemiological Aspects of Fascioliasis among Cattle of Ladakh. Global Veterinaria 7(4): 342-346.

14. Graber M, Michael A, Solomon D (2005) Helminthes and Helminthiasis of Domestic and Wild Animal in Ethiopia. Revue Elev Med Vet Pays Trop 1: 13-95.

15. Tadesse T, Worku T (2007) The Prevalence and Economic Significant of Bovine Fasciolosis at Jimma Abattoir, Ethiopia. The internate J vet Med 3: 15 .
This work is licensed under Creative Commons Attribution 4.0 License

Submission Link: Submit Article

DOI: $10.32474 /$ CDVS.2019.02.000139

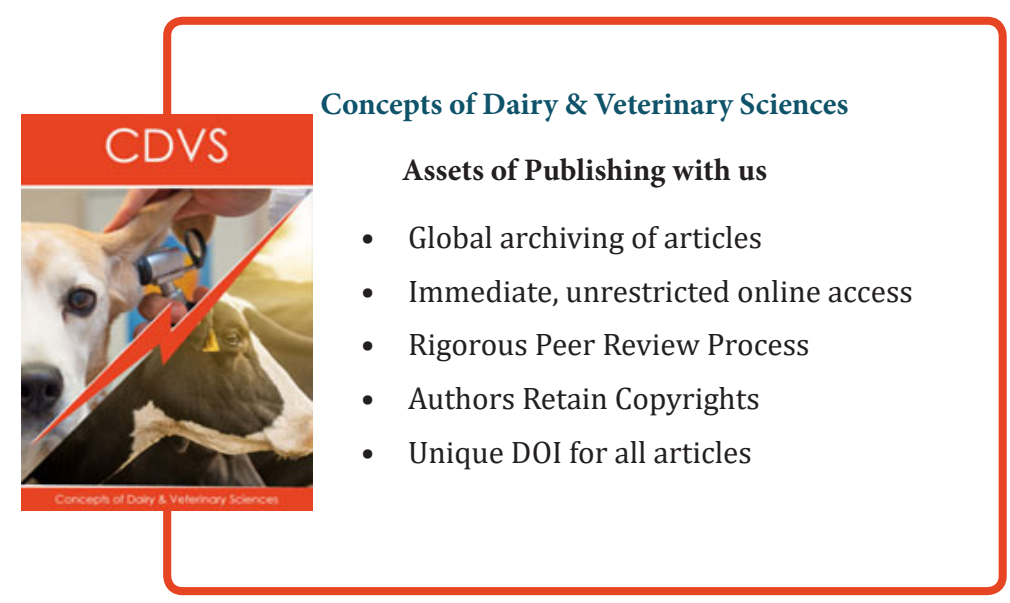

